\title{
4 Epilegomena: Concluding Remarks and Implications
}

\author{
"It is not enough for peace and concord to be \\ preserved among men by precepts of justice, \\ unless there be a further consolidation of mutual love." \\ St. Thomas Aquinas (ScG, lib. 2 cap. 28 n. 3)
}

This book has set out to find an answer to the question of whether assuming that human rights are the moral rights of all human beings of all times and are directly grounded in human dignity - health can be conceptualised as a human right from a philosophical perspective. As our enquiries have shown, the answer to this question is that health cannot be a human right. Health has nothing to do with that aspect of our dignity, which alone is capable of grounding unconditioned human rights, namely ontological dignity. Stating the opposite would be wishful thinking or an empty political formula and would mean to arbitrarily neglect philosophically sound evidence to the contrary. The stipulation that "health is a fundamental human right" (CESCR, General Comment No. 14), which "derive(s) from the inherent dignity of the human person" (ICESCR, Preamble) is thus - from a philosophical point of view - nonsensical and untenable.

However, our enquiries have also shown that health can be thought of as a moral passive negative claim-right to health as state which combines a moral negative claim-right to health as habit as well as a moral negative claim-right that those, whose behaviour, actions or decisions have an influence on those determinants of health, which cannot be influenced by the right-holder, must not engage in or choose behaviours, actions or decisions, which harm or worsen the right-holder's state of health. The relationship between health and (moral) rights is, therefore, a multidimensional one. Given its passive negative nature, the moral right to health just mentioned is rather limited in scope; it is not a right to a minimal amount of health or the improvement of health but imposes on the duty-bearers the behavioural constraint to not worsen or harm the health of the right-holder or hinder his salutogenic health habits. Essentially, it is a right to be left alone and cannot be used to demand any positive welfarist action on the part of the corresponding duty-bearer. 
These findings do not only open up the space for philosophical discussion, but are also of practical relevance. Accepting the argument developed in this essay must necessarily result in the concerted effort of politicians, philosophers and health care professionals to rethink the foundation of our health care policies and systems as well as the organisation of global health in general. In order to shape them in a sustainable fashion, we need to be aware of what we reasonably owe to each other when it comes to health; and this requires us to comprehend what we are saying when we use words like 'right', 'duty', 'dignity', 'person' or 'health'. Politics must not be a music request programme ('Wunschkonzert'), which expands the list of human rights in an uncontrolled fashion, but must rather orientate by certain moral guidelines. In addition, if international and national law wants human dignity to be one of these guidelines, it has to aim at understanding the concept of dignity and - once understood - stick to it and its implications. Human rights law can only command moral power if it is not only legally, but also philosophically sound; presently, this soundness is rather doubtful and must be reconstructed. How such reconstruction could look is a salient topic for further research.

Another point worthy of further discussion and research is every person's duty to health. The existence of this duty forces us to think about ways by which to hold a person morally accountable for violations of this duty and how to attribute the (treatment) costs for unhealth resulting from such violations. Doing so requires an understanding of the relationship and differences between the concepts of duty and responsibility - or as Birnbacher (2001) calls them 'ex ante responsibility' (= duty) and 'ex post responsibility' (= responsibility). As has been said, a duty is a behavioural constraint, which is meant to regulate our behaviour by prescribing what we ought to do or refrain from doing. However, it does not deprive us of behavioural choices; it is a constraint, but not duress or coercion. We are free to fulfil or not fulfil our duties and in a position to choose from among the various means of fulfilment. Strange as it may sound, a duty implies choice. And where there is choice, there is responsibility, which is nothing 
else than bearing the consequences of one's actions and choices. ${ }^{281}$ Subsequent work could apply existing accounts of exemptions from (ex post) responsibility (e.g. Erk (2009b) or Scanlon (1998: 280ff)) to the concept of health as duty: When and under which circumstances can someone be held accountable for his health status and behaviour? When and under which circumstances can someone be exempted from bearing the costs of unhealthy behaviour? These are the questions, which would have to be addressed in such an endeavour. Given our rising healthcare costs, higher burdens of chronic unhealth as well as undeniable and increasing evidence about the contribution of behavioural factors to unhealth, the issue of personal responsibility for health is here to stay and most important.

However - and this is very important - all the talk about rights and duties must not make us forget that rights talk - though important - only captures a fracture of what is important in our moral relationships with each other and runs the risk of compromising the common good. That this is so can easily be seen by the fact that the first hospitals have not been multi-billion dollar enterprises, but institutions of Christian charity (cf.

281 Although the terminology varies, philosophers generally think of such moral responsibility as having two aspects. They draw a distinction between responsibility understood as attributability (or "substantive responsibility" in Scanlon's (1998: 248) or"causal responsibility" in Williams (2009) terms) and responsibility as accountability (or 'appraisability' according to some terminologies). The former is concerned with ascribing an agent a causal role in bringing about what is then to be evaluated from the standpoint of accountability, i.e. moral appraisal. (cf. Watson, 1996; Scanlon, 1998: 248ff; Eshleman, 2009). We are responsible in a substantive sense for the outcome and consequences of our actions if and precisely because we have chosen them. This is the burden of the value and significance we attribute to our freedom to choose. However, the fact that somebody has chosen an action and is substantively responsible does not automatically imply 'responsibility as accountability'. (Nota bene: Instead 'responsibility as accountability' Scanlon uses "responsibility as attributability" (Scanlon, 1998: 248).) We can ascribe a chosen action to somebody (i.e. make him responsible in a substantive sense), but still hold that he is not morally blameworthy. For a discussion of these exceptional cases cf. Erk (2009b). 
Crislip, 2005), and that the idea of health insurance was not a product offered by a profit seeking insurance company, but has its roots in the mediaeval guild system and the mutual care of a guild's members (cf. Oberender, Hebborn \& Zerth, 2002: 20f). What we call 'health system' has formerly not been about rights and claims, but other values, such as charity, friendship, kindness, solidarity and cooperation.

"A line must be drawn between what we can expect and demand from others and what we can merely hope for and receive with gratitude when we get it; duty falls on one side of this line, and other acts with moral value on the other, and rightly so." (Urmson, 1958: 213)

There might not be any moral positive claim-rights obliging others to give away some of their honestly earned resources, but there nevertheless are other moral motivators, which can goad us to actively help others and voluntarily devote some of our resources to them - actions, which Urmson (1958: 211, 215) calls "higher flights of morality". ${ }^{282}$ Maybe living in society is not so much about the rights and duties, but much more about the spirit in which the rights and duties are performed and whether the individuals comprised by it are willing to rise above the moral minimalism, which is expressed by moral rights and duties. We should not aim at maximising rights or at trying to get rid of our reasonably justified duties, but rather try to become heroes and saints.

${ }^{282}$ Such actions are usually called 'supererogatory' or 'opera supererogationis'. The term 'supererogation' derives from the Gospel according to Luke and its Parable of the Good Samaritan (10,30-35), where we can read the following sentence: "Curam illius habe, et quodcumque supererogaveris ego cum rediero reddam tibi." (This translates as: Care for him; and if you spend more than I have given you, I shall repay you when I return.) A supererogatory work is therefore done if one carries out one's duty in abundance or even super-abundance, i.e. does more than he is obliged to do (also cf. Heyd, 2006). 
